\title{
Implant-associated anaplastic large cell lymphoma of the breast: Insight into a poorly understood disease
}

\author{
William M Weathers MD, Erik M Wolfswinkel BS, Daniel A Hatef MD, \\ Edward I Lee MD, Larry H Hollier MD, Rodger H Brown MD
}

\begin{abstract}
WM Weathers, EM Wolfswinkel, DA Hatef, EI Lee, LH Hollier, RH Brown. Implant-associated anaplastic large cell lymphoma of the breast: Insight into a poorly understood disease. Can J Plast Surg 2013;21(2):95-98.

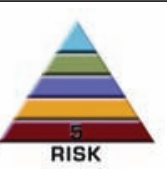

Implant-associated anaplastic large cell lymphoma (ALCL) is the subject of much debate in the field of plastic surgery. Only a few published cases have been reported and the rarity of the disease may make proving causality exceedingly difficult. Despite this, it is of utmost importance that full attention be devoted to this subject to ensure the safety and well-being of patients. The authors report one new case of implant-associated ALCL that recently presented to their institution. Implant-associated ALCL is a poorly understood disease. It should likely be considered its own clinical entity and categorized into two subtypes: one presenting as a seroma and the other as a distinct mass or masses. When reported, only textured implants have been associated with ALCL. The United States Food and Drug Administration and American Society of Plastic Surgeons have initiated a registry and have collected critical data to gain further understanding of this disease.
\end{abstract}

Key Words: Anaplastic large cell lymphoma; Breast implant; Lymphoma; Seroma
A naplastic large cell lymphoma (ALCL) is the subject of increas- ing scrutiny among plastic surgeons and the public. Accounting for only $3 \%$ of all non-Hodgkin's lymphoma and $0.5 \%$ of all breast cancers, ALCL is rare (1-4). Multiple reports have highlighted a pos- sible relationship between ALCL in the breast and breast implants. In January 2011, the United States Food and Drug Administration (FDA) published an investigation of ALCL and breast implants, which concluded that there is a possible association between breast implants and ALCL; however, the low incidence of ALCL - 0.1 to 0.3 per 100,000 - would make proving causality exceedingly difficult $(5,6)$. A multidisciplinary panel of experts reached a similar conclu- sion $(7,8)$, suggesting an association without a causal relationship between breast implants and ALCL. Other than asserting that an association between implants and ALCL likely exists, no clear consen- sus regarding ALCL and breast implants has emerged.
In the literature, contributing factors for implant-associated ALCL have not been established. Of the known cases of ALCL associated with implants, both saline and silicone implants have been docu- mented (5). It has been reported in patients both receiving implants for cosmetic purposes and for reconstruction secondary to cancer (9). Time to presentation after placement of breast implants has ranged from one to 23 years, and patients' age has ranged from 28 to 87 years (6). The most consistent association is that all cases of breast implant- associated ALCL in which cytology is known, demonstrate strong CD30 positivity and are anaplastic lymphoma kinase-1 (ALK-1) nega- tive $(5,7,10)$. Continued vigilance in reporting cases is needed to fur- ther elucidate possible contributing factors.
The majority of what is known about ALCL is derived from case reports. The data from these reports are somewhat limited in that not all contain complete details. A standard work-up for suspected new

\author{
Le lymphome anaplasique à grandes cellules associé \\ à un implant mammaire : aperçu d'une maladie mal \\ comprise
}

Le lymphome anaplasique à grandes cellules (LAGC) associé à un implant mammaire suscite d'abondants débats en chirurgie plastique. Seuls quelques cas publiés ont été signalés et, en raison de la rareté de la maladie, il est très difficile d'en prouver la causalité. Pourtant, il est capital de se pencher sérieusement sur le sujet afin de garantir la sécurité et le bien-être des patients. Les auteurs rendent compte d'un récent cas de LAGC associé à un implant mammaire au sein de leur établissement. Le LAGC associé à un implant mammaire est une maladie mal comprise. Il faudrait probablement le considérer comme une entité clinique distincte et le classer en deux sous-types : l'une se manifestant sous forme de sérome et l'autre, sous forme de masse(s) distincte(s). Seuls les implants texturés s'y associent. La Food and Drug Administration des États-Unis et l'American Society of Plastic Surgeons ont créé un registre et colligé des données essentielles pour mieux comprendre cette maladie.

cases has been recommended by the FDA to ensure that all pertinent information is obtained from each case in the future (5). This will ensure accurate and complete information, and further the study of ALCL and its relationship with breast implants. Using these new recommendations, we present one case of implant-associated ALCL that presented to our facility.

\section{CASE PRESENTATION}

A 44-year-old female underwent bilateral subglandular breast augmentation in 2005 in Mexico with 410 mL CUI round-textured silicone implants (Allergan, USA) through an inframammary approach. The patient experienced no immediate postoperative complications and had an uneventful course until her presentation to the Ben Taub General Hospital (Texas, USA) seven years after surgery.

In 2012, the patient presented to the Ben Taub General Hospital emergency department complaining of progressive left breast swelling and erythema for three months. The patient denied fever, chills or symptoms of systemic toxicity. The patient had no recent history of trauma or breastfeeding. On presentation, the patient was afebrile and hemodynamically stable. Her white blood cell count was $5 \times 10^{9} / \mathrm{L}$. Physical examination revealed significant enlargement of the left breast relative to the right (Figure 1). Mild erythema at the superior, medial and lateral poles of the left breast was present. There was no expressible drainage from the nipple and no focal areas of induration. She exhibited general tenderness to palpation over the left breast. Physical examination of the right breast was unremarkable.

At this time, an ultrasound was obtained that demonstrated a large fluid collection in the posterior left breast with a stair-step appearance of the implant wall (Figure 2). These findings were concerning for extracapsular rupture. A subsequent computed tomography (CT) scan 


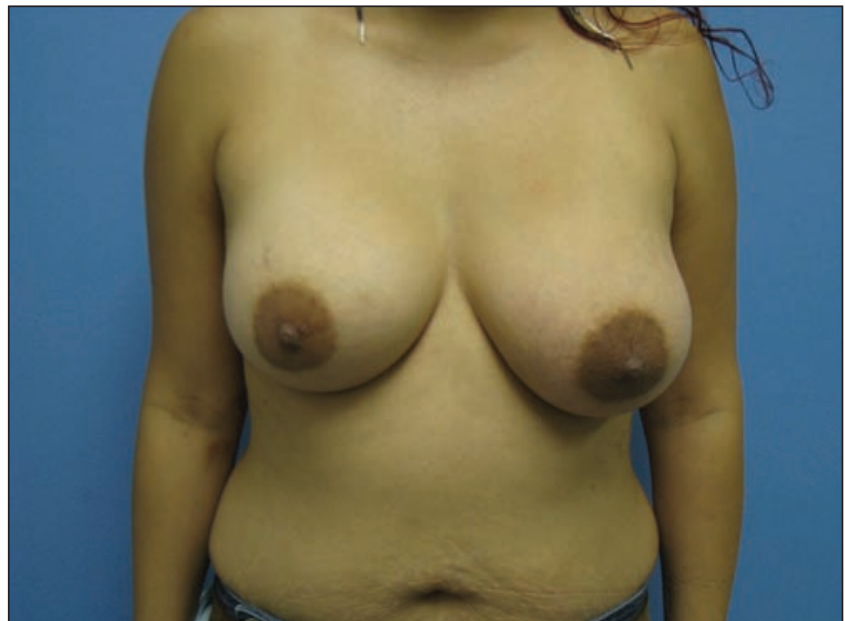

Figure 1) Frontal view demonstrating left breast enlargement
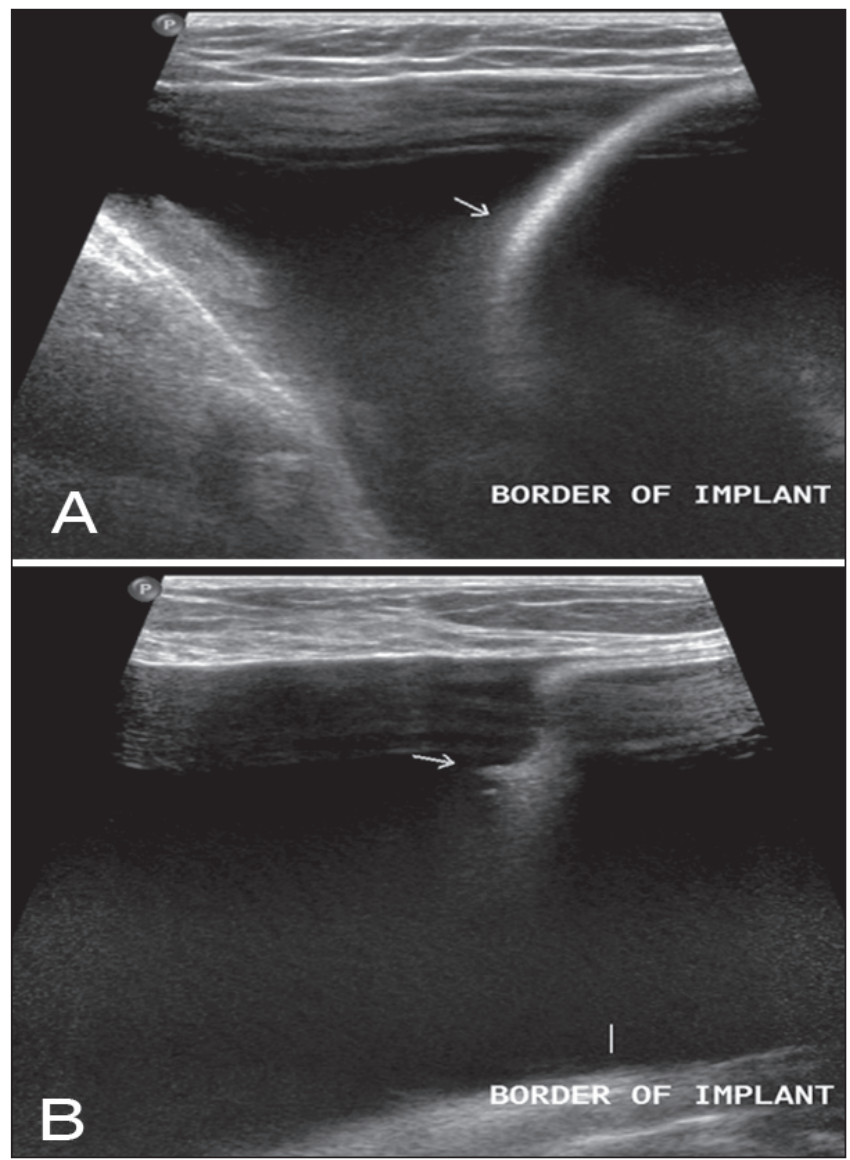

Figure 2) Ultrasound evaluation of the left breast demonstrating fluid posterior to the implant suspicious for extracapsular rupture (arrow) (A). B Stairstep appearance of the implant wall, suspicious for rupture (arrow)

of the chest was obtained, which demonstrated a nonenhancing, simple periprosthetic fluid collection $(18 \mathrm{~cm} \times 10 \mathrm{~cm} \times 15 \mathrm{~cm})$ and irregular contour of the implant (Figure 3 ). These findings also suggested extracapsular implant rupture. Ultrasound-guided aspiration yielded $1200 \mathrm{~mL}$ of light-yellow fluid, which was sent for cytology and culture as recommended in the literature (11-13). Cytology revealed features consistent with ALCL and CD30 positivity, and was negative for ALK-1. Table 1 summarizes the full cytological results.

The patient was educated about her diagnosis and all treatment options. She was seen by the medical oncology service. A staging CT scan of the chest, abdomen and pelvis revealed no evidence of nodal

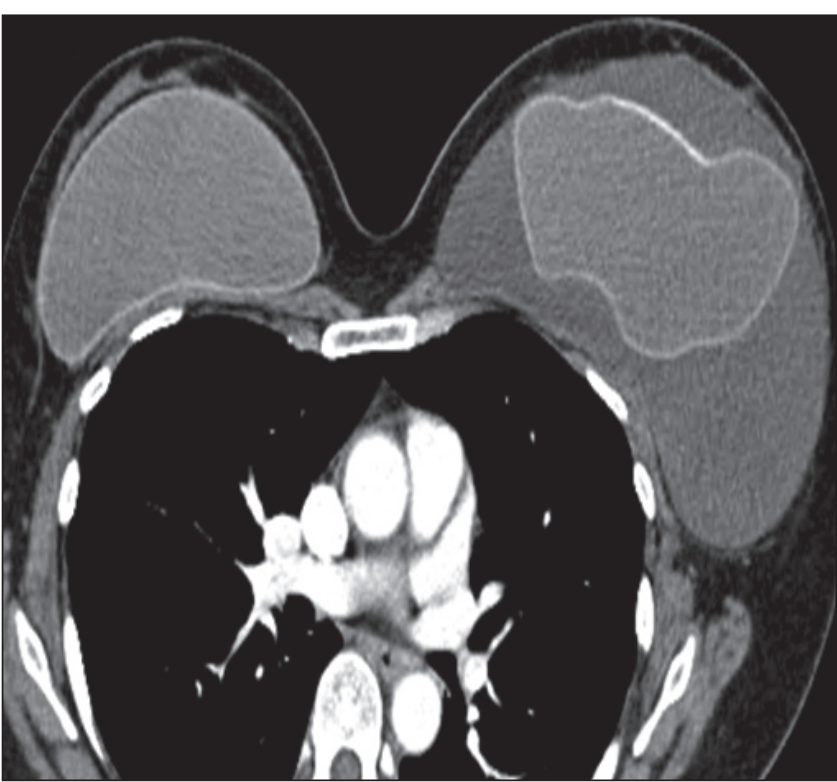

Figure 3) Contrast-enhanced computed tomography of the chest demonstrating a simple fluid collection and irregular contour of the implant wall, suspicious for implant rupture

TABLE 1

Cytology results for ultrasound-guided aspirate

\begin{tabular}{ll}
\hline Positive & Negative \\
\hline CD30, Granzyme, CD3, CD4, CD43, & ALK-1, CD8, CD20, CD5, EMA \\
CD45, CD2 (subset), Ki-67 & \\
(approximately 90\%) &
\end{tabular}

ALK-1 Anaplastic lymphoma kinase-1; EMA Epithelial membrane antigen

involvement or disease spread. At this time, it was believed that the patient would benefit from bilateral implant removal and complete capsulectomy.

She was taken to the operating room and the right side implant was removed along with the surrounding capsule. The implant was intact and was revealed to be a $410 \mathrm{~mL}$ textured silicone implant (CUI Corporation, USA). The capsule was entered on the left side and 200 $\mathrm{mL}$ of straw-coloured fluid was drained and sent for cytology (Figure 4). A weak capsule was apparent around the anterior portion of the implant and a thicker double capsule was encountered posteriorly. The entire capsule was removed and sent for permanent pathology (Figure 5). There was no evidence of invasion or involvement of the surrounding breast parenchyma.

Pathology of the capsule and implant were negative for malignancy, but the intracapsular seroma fluid again showed findings consistent with implant-associated ALCL. The patient had an uneventful recovery and is currently free of any sign of recurrence. After review of the surgical pathology, the oncology service does not believe that adjuvant chemotherapy or radiation is necessary. She is being followed closely by the oncology service with an ultrasound examination every three months and breast magnetic resonance imaging in six months.

\section{DISCUSSION}

Debate continues with regard to the relationship between breast implants and ALCL. Five large epidemiological studies following 43,537 women with breast implants from 1953 to 1999 (14-18) did not find an increased risk of lymphoma associated with breast implants. In contrast, De Jong et al (6) found an increased risk of ALCL with breast implants $(\mathrm{OR}=18.2)$ when compared with control groups of women with other forms of breast lymphoma. Although these results are statistically striking, they should not be interpreted to mean that women with breast implants are at increased risk of ALCL because the 


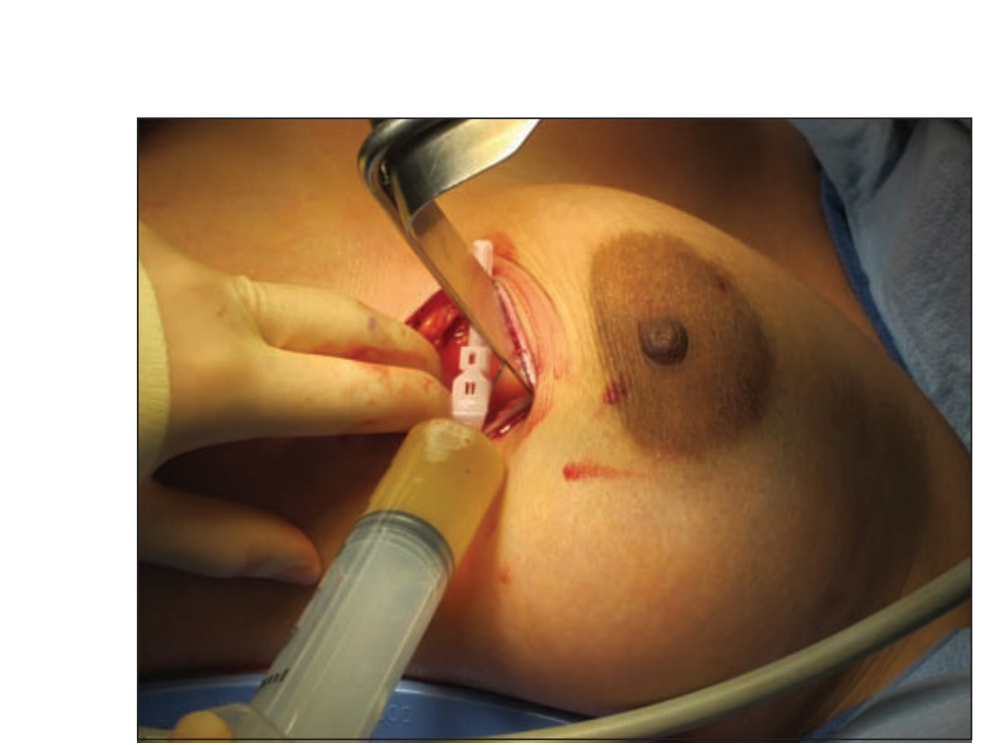

Figure 4) Intraoperative drainage of remaining seroma

selection of the control group only included non-ALCL lymphomas of the breast (17). Despite the lack of causative evidence behind implant-associated ALCL, it is difficult to ignore the possibility of a causal relationship. Some authors argue that a link must exist between the two given that there is a reversal of the ratio of $\mathrm{B}$ cell lymphoma to $\mathrm{T}$ cell lymphoma in women with breast implants compared with the general population $(6,19,20)$. Unfortunately, the rarity of this disease will make proving causality challenging, if not impossible.

ALCL is a universally CD $30^{+}$lymphoma that is a result of abnormal activation and proliferation of $\mathrm{T}$ lymphocytes $(5,21)$. ALCL is currently classified into two types: cutaneous ALCL and systemic ALCL (22). Rearrangement of the anaplastic lymphoma kinase gene $(\mathrm{ALK}-1)$ further characterizes the ALCL subtypes and dictates prognosis. ALK-1(+) ALCL has a 10-year survival rate of $90 \%$, whereas ALK-1(-) ALCL carries a reported five-year survival rate of $35 \%$ to $49 \%(23,24)$. Cutaneous ALCL is almost always ALK-1(+) and Systemic ALCL is ALK-1(+) in $60 \%$ to $85 \%$ of cases (24-26). ALK-1(+) cytology bestows a much better prognosis. Clinically, cutaneous ALCL presents with localized skin tumours or nodules and is usually stage IE or IIE at time of diagnosis $(22,23)$. The majority of ALK-1(-) systemic ALCL cases present with painless peripheral lymphadenopathy, B symptoms and stage III or IV disease (23). Implant-associated ALCL overwhelmingly presents as unilateral breast swelling and effusions $(9,10)$.

Breast implant-associated ALCL should be classified as its own distinct clinical entity $(8,10,19,27,28)$. It shares features of both systemic and cutaneous ALCL, but does not truly fit into either disease category. Breast implant-associated ALCL has similar morphology and cytology to ALK-1(-) systemic ALCL. However, ALK-1(-) systemic ALCL has a poor prognosis, while ALK-1(-) ALCL associated with implants is typically an indolent disease amenable to treatment (9). Despite sharing a similar prognosis with cutaneous ALCL, the cytology is different because most cutaneous ALCL is ALK-1(+). Another distinguishing factor is that a majority of these cases present as a unilateral late-onset seroma with generalized swelling of the breast. This presentation is inconsistent with the clinical presentation of both cutaneous and systemic ALCL (10).

Not only should implant-associated ALCL be classified as its own entity, it may be prudent to further characterize it into categories based on clinical presentation (seroma versus mass). Implant-associated ALCL presenting with a seroma has not been implicated in any deaths and typically resolves with implant removal and capsulectomy. In some cases, neoadjuvant chemotherapy and radiation have been used as a supplement (9). A recent case report by Carty et al (29) described the first death as a result of breast implant-associated ALCL. This case presented as a periprosthetic necrotic mass without a seroma that subsequently metastasized despite multiple rounds of chemotherapy and

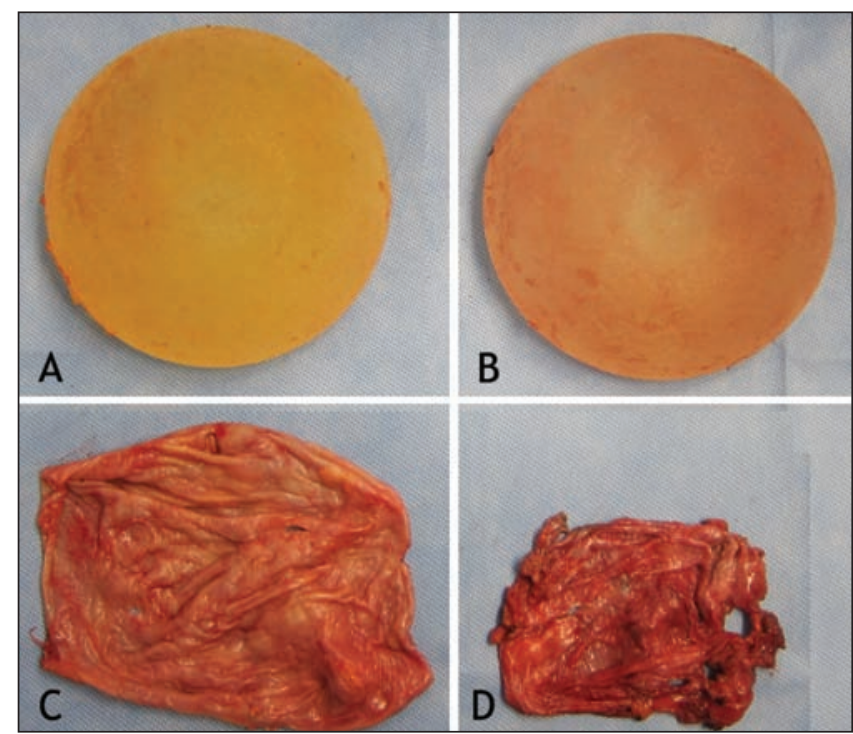

Figure 5) Gross photographs of the bilateral breast implants and capsules. Anaplastic large cell lymphoma was confirmed in the left breast. A Left implant. B Right implant. C Left capsule. D Right capsule

radiation. Another case of implant-associated ALCL that resulted in a more aggressive course presented with multiple subcutaneous nodules. This case had no associated seroma and ultimately resulted in systemic dissemination of disease $(27,30)$. A patient that presents with a distinct periprosthetic mass instead of a seroma may indicate a more aggressive implant-associated ALCL, similar to that of ALK-1(-) systemic ALCL and, therefore, may necessitate aggressive treatment and close observation $(29,31)$.

Recently, implant texture has been called into question for implant-associated ALCL. All cases of implant-associated ALCL in which surface type is known have reported textured implants as the type of implant $(28,32)$. It is well known that textured implants have been associated with late-onset seromas but their association with ALCL is less clear $(12,33)$. Because ALCL is a result of T cell activation and expansion, some have argued that ALCL may be a result of an immunogenic response (27). However, direct antigenic stimulation is unlikely because ALCL cells have been found to lack a T cell receptor signalling system (34). Additional studies are needed to determine how textured implants could lead to $\mathrm{T}$ cell proliferation and eventual oncongenic transformation. Although no epidemiological data supporting an increased risk of lymphoma with breast implants exist, some have argued that this is secondary to lack of inclusion of patients with textured implants. Most of the epidemiological data were derived from studies spanning the period from the 1950s to the 1990s, and textured implants did not become widely used until the 1990s. Taylor et al (28) postulate that the lack of epidemiological data for increased risk of lymphoma with breast implants may be the result of a lack of inclusion of textured implants because they did not come into common use until the 1990s.

Initial management of late-onset seromas associated with breast implants has evolved since the discovery of a possible link with ALCL. Data from early case reports regarding ALCL and breast implants were often incomplete and inconsistent. This has made it difficult to analyze the cases in the literature. Initial management of a late-onset seroma or peri-implant mass associated with a breast implant has evolved into a more standardized approach (11-13). In an attempt to gather consistent data from case to case for analysis, the FDA and the American Society of Plastic Surgeons recommend collecting and reporting specific data to their registry (Table 2) (5). With standardized initial management approaches, data collection will be improved and help in our understanding and analysis of this disease entity. 
TABLE 2

Data to be collected when reporting to the United States Food and Drug Administration

\begin{tabular}{ll}
\hline Category & Data \\
\hline $\begin{array}{l}\text { Demographics } \\
\text { Clinical presentation }\end{array}$ & $\begin{array}{l}\text { Age, sex, ethnicity/race } \\
\text { Onset, } \pm \text { swelling, erythema, } \pm \text { mass, length of } \\
\text { time after implant placement } \\
\text { Detailed pathology }\end{array}$ \\
$\begin{array}{l}\text { Cytology results from seroma, capsule or peri- } \\
\text { implant mass, gross pathology and histology of } \\
\text { implant capsule and/or peri-implant mass }\end{array}$ \\
Breast implant & $\begin{array}{l}\text { Date implanted, brand, type (silicone, saline), } \\
\text { implant surface, complications, revision surgeries }\end{array}$ \\
ALCL diagnosis & $\begin{array}{c}\text { Date of diagnosis, anatomical site of ALCL, } \\
\text { whether it is primary in this site }\end{array}$ \\
Treatment & Chemotherapy, surgery
\end{tabular}

ALCL Anaplastic large cell lymphoma

\section{CONCLUSION}

Implant-associated ALCL is a poorly understood disease. It is likely that breast implant-associated ALCL is a distinct entity from either systemic or cutaneous ALCL. Any time a woman presents with a seroma six months or later following breast implants, aspiration of fluid for culture and cytology should be performed. Further investigation into the possible role of implant texturing in the etiology of ALCL is clearly indicated. Given these developments, in our opinion, a discussion of ALCL should be a part of the informed consent process for any patient undergoing breast implant surgery.

DISCLOSURES: The authors have no financial disclosures or conflicts of interest to declare.

\section{REFERENCES}

1. Armitage JO. A clinical evaluation of the International Lymphoma Study Group classification of non-Hodgkin's lymphoma.

Blood 1997;89:3909-18.

2. Brogi E, Harris NL. Lymphomas of the breast: Pathology and clinical behavior. Semin Oncol 1999;26:357-64.

3. Cohen PL, Brooks JJ. Lymphomas of the breast. A clinicopathologic and immunohistochemical study of primary and secondary cases. Cancer 1991;67:1359-69.

4. Wiseman C, Liao KT. Primary lymphoma of the breast. Cancer 1972;29:1705-12.

5. U.S. Food and Drug Administration, U.S. Department of Health and Human Services. FDA medical device safety communication: Reports of anaplastic large cell lymphoma (ALCL) in women with breast implants. Silver Spring, Md: U.S. Food and Drug Administration. January 26, 2011. <www.fda.gov/medicaldevices/safety/ alertsandnotices/ucm240000.htm> (Accessed January 1, 2013).

6. De Jong D, Vasmel WLE, De Boer JP, et al. Anaplastic large-cell lymphoma in women with breast implants. JAMA 2008;300:2030-5.

7. Kim B, Roth C, Chung KC, et al. Anaplastic large cell lymphoma and breast implants: A systematic review. Plast Reconstr Surg 2011;127:2141-50.

8. Kim B, Roth C, Young VL, et al. Anaplastic large cell lymphoma and breast implants: Results from a structured expert consultation process. Plast Reconstr Surg 2011;128:629-39.

9. Kim B, Roth C, Chung KC, et al. Anaplastic large cell lymphoma and breast implants: A systematic review. Plast Reconstr Surg 2011;127:2141-50.

10. Jewell M, Spear SL, Largent J, et al. Anaplastic large T-cell lymphoma and breast implants: A review of the literature. Plast Reconstr Surg 2011;128:651-61.

11. Bengtson B, Brody GS, Brown MH, et al. Managing late periprosthetic fluid collections (seroma) in patients with breast implants: A consensus panel recommendation and review of the literature. Plast Reconstr Surg 2011;128:1-7.

12. Spear SL, Rottman SJ, Glicksman C, et al. Late seromas after breast implants: Theory and practice. Plast Reconstr Surg 2012;130:423-35.

13. Tebbetts JB. Diagnosis and management of seroma following breast augmentation: An update. Plast Reconstr Surg 2011;128:17-25.
14. Brinton LA, Lubin JH, Burich MC, et al. Cancer risk at sites other than the breast following augmentation mammoplasty. Ann Epidemiol 2001;11:248-56.

15. Brisson J, Holowaty EJ, Villeneuve PJ, et al. Cancer incidence in a cohort of Ontario and Quebec women having bilateral breast augmentation. Int J Cancer 2006;118:2854-62.

16. Deapen DM, Hirsch EM, Brody GS. Cancer risk among Los Angeles women with cosmetic breast implants. Plast Reconstr Surg 2007;119:1987-92.

17. Lipworth L, Tarone RE, McLaughlin JK. Breast implants and lymphoma risk: A review of the epidemiologic evidence through 2008. Plast Reconstr Surg 2009;123:790-3.

18. Pukkala E, Boice Jr JD, Hovi SL, et al. Incidence of breast and other cancers among Finnish women with cosmetic breast implants, 1970-1999. J Long-Term Eff Med 2002;12:271-9.

19. Thompson PA, Lade S, Webster H, Ryan G, Prince HM. Effusionassociated anaplastic large cell lypmhoma of the breast: Time for it to be defined as a distinct clinico-pathological entity. Haematolgica 2010; 95:1977-9.

20. Miranda RN, Lin L, Talwalkar SS, et al. Anaplastic large cell lymphoma involving the breast: A clinicopathologic study of 6 cases and review of the literature. Arch Pathol Lab Med 2009;133:1383-90.

21. Smith CA, Gruss HJ, Davis T, et al. CD30 antigen, a marker for Hodgkin's lymphoma, is a receptor whose ligand defines an emerging family of cytokines with homology to TNF. Cell 1993; 73:1349-60.

22. Harris NL, Jaffe ES, Diebold J, et al. World health organization classification of neoplastic diseases of the hematopoietic and lymphoid tissues: Report of the clinical advisory committee meeting - Airlie house, Virginia, November 1997. J Clin Oncol 1999;17:3835-3849.

23. Savage KJ, Harris NL, Vose JM, et al. ALK ${ }^{-}$anaplastic large-cell lymphoma is clinically and immunophenotypically different from both ALK+ ALCL and peripheral T-cell lymphoma, not otherwise specified: Report from the International Peripheral T-Cell Lymphoma Project. Blood 2008;111:5496-504.

24. Ten Berge RL, Oudejans JJ, Ossenkoppele GJ, et al. ALK expression in extranodal anaplastic large cell lymphoma layouts systemic disease with (primary) nodal involvement and a good prognosis and occurs before dissemination. J Clin Pathol 2000;53:445-50.

25. DeCoteau JF, Butmarc JR, Kinney MC, et al. The t $(2 ; 5)$ chromosomal translocation is not a common feature of primary cutaneous $\mathrm{CD} \mathrm{O}^{+}$lymphoproliferative disorders: Comparison with anaplastic large-cell lymphoma of nodal origin. Blood 1996;87:3437-41.

26. Pittaluga S, Wlodarska I, Pulford K, et al. The monoclonal antibody ALK1 identifies a distinct morphological subtype of anaplastic large cell lymphoma associated with 2p23/ALK rearrangements. Am J Pathol 1997;151:343-51.

27. Roden AC, Macon WR, Keeney GL, et al. Seroma-associated primary anaplastic large-cell lymphoma adjacent to breast implants: An indolent T-cell lymphoproliferative disorder. Modern Pathol 2008;21:455-63.

28. Taylor KO, Webster HR, Prince HM. Anaplastic large cell lymphoma and breast implants: Five Australian cases. Plast Reconstr Surg 2012;129:610e-617e.

29. Carty MJ, Pribaz JJ, Antin JH, et al. A Patient death attributable to implant-related primary anaplastic large cell lymphoma of the breast. Plast Reconstr Surg 2011;128:112e-118e.

30. Gaudet G, Friedberg JW, Weng A, et al. Breast lymphoma associated with breast implants: Two case-reports and a review of the literature. Leuk Lymphom 2002;43:115-9.

31. Aladily TN, Medeiros JL, Amin MB, et al. Anaplastic large cell lymphoma associated with breast implants: A report of 13 cases. Am J Surg Pathol 2012;36:1000-8.

32. Brody G, Deapen D, Gill P, Epstein A, Martin S, Elatra W. T-cell non-Hodgkin's anaplastic lymphoma associated with one style of breast implants. AAPS 89th Annual Meeting, San Antonio, March 20 to 23, 2010.

33. Hall-Findlay EJ. Breast implant complication review: Double capsules and late seromas. Plast Reconstr Surg 2011;127:56-66.

34. Bonzheim I, Geissinger E, Roth S, et al. Anaplastic large cell lymphomas lack the expression of T-cell receptor molecules or molecules of proximal T-cell receptor signaling. Blood 2004;104:3358-60. 